\title{
Deep-Elaborative Learning of Introductory Management Accounting for Business Students
}

\author{
Freddie Choo, (Email: fchoo@sfsu.edu ), San Francisco State University
}

Kim B. Tan, (Email: KTan@stan.csustan.edu ), California State University Stanislaus

\begin{abstract}
Research by Choo and Tan (1990; 1995) suggests that accounting students, who engage in deep-elaborative learning, have a better understanding of the course materials. The purposes of this paper are: (1) to describe a deep-elaborative instructional approach (hereafter DEIA) that promotes deep-elaborative learning of introductory management accounting for business students, and (2) to report the relationship between the DEIA and the students' learning and recommendation of the DEIA in introductory management accounting.
\end{abstract}

\section{Introduction}

12

esearch by Choo and Tan (1990; 1995) suggests that accounting students, who engage in deep-elaborative learning, have a better understanding of course materials. Deep-elaborative learning simply means that the students learn to think more deeply and extensively of the course materials. The purposes of this paper are: (1) to describe a deep-elaborative instructional approach (hereafter DEIA) that promotes deep-elaborative learning of introductory management accounting for business students, and (2) to report an analysis of the relationship between the DEIA and the students' performance and recommendation of the DEIA in introductory management accounting.

\section{The Deep-Elaborative Instructional Approach (DEIA)}

The DEIA consists of four phases:

1. Introduce students to the common terminology for a particular management accounting topic.

2. Explain the equation(s) that represent the management accounting topic.

3. Assign students to solve the equation(s) repetitively by using spreadsheet.

4. Recycle the equation(s) across multiple management accounting topics so that students get repeated exposures to the same equation(s).

An advantage of the DEIA is that the instructor can identify more precisely in which phase the students are having difficulty in their learning. For example, the instructor can identify whether the students are having difficulty in understanding the equations (i.e., phase 2), and/or in solving the equations (i.e., phase 3). By identifying in which phase a student has difficulties with, the instructor will 
be better able to help that student overcome his/her learning difficulties. ${ }^{1}$ Another advantage of the DEIA is that the instructor can incorporate the spreadsheet technology into introductory management accounting, and can teach the students to prepare professional reports. According to Böer (2000), technology that incorporates spreadsheet reporting will be one of the driving forces in changing management accounting. Employers prefer to employ business graduates that can prepare and understand spreadsheet reports. DEIA here.

The topic of job order costing in introductory management accounting is used to illustrate the

\section{Phase 1: Introduce Terminology}

The DEIA starts out by introducing students to the common terms used in job order costing. These terms include direct materials, direct labor, overheads, and product/manufacturing costs. Several instructional notes relating to the introduction of these terms are:

1. Introductory management accounting textbooks usually provide a section on the common terms used in a particular management accounting topic. The instructor should use this section to introduce the terminology to students.

2. The instructor should tell the students that they should know the terminology ${ }^{2}$ well because it facilitates their reading and understanding of the management accounting topic.

3. The instructor should explain these terms to the students in as simple a way as possible. ${ }^{3}$

4. The learning of terminology should be a cumulative process. ${ }^{4}$

\section{Phase 2: Explain Equations}

First, the instructor describes the job order environment to the students. The instructor draws a simple plan of the three major sections of a manufacturing company as shown in Figure 1 . These sections are - a materials warehouse, a work-in-process factory floor, and a finished goods warehouse. When materials are purchased, they are stored in the materials warehouse. Then the materials are transferred to the work-in-process factory floor, where they are combined with labor and overheads to become finished goods. Finished goods on the factory floor are then transferred to and stored in the finished goods warehouse. The finished goods are transferred to customers when a sale is made.

Figure 1 shows that the three sections are related because of the physical movements (or transfers) that take place as manufacturing progresses. The physical movements shown as arrows in

$1 \quad$ If students have difficulties in solving equations (i.e., phase 3), the instructor should help to improve their algebra skills. If students have difficulties in understanding equations (i.e., phase 2), the instructor should better explain the equations.

${ }_{2}$ The learning of new terminology is important so that all students in the class are operating on the same wavelength. The instructor should remind students that they have learnt new terminology in many of their other courses. For example, they have learnt new terminology in their biology, geography, physics, computer, algebra, and trigonometry classes. Therefore, they should not have much difficulty in learning new management accounting terminology.

3 The instructor should describe the new terms by incorporating day-to-day examples. For example, the term "variable costs" can be explained by relating it to the total costs of buying apples in the supermarket, or by drawing a simple graph of the variable costs relationship.

$4 \quad$ The instructor should use the terms consistently across multiple management accounting topics so that students can build up their knowledge base of terms over time. 
Figure 1 are: (1) materials in the materials warehouse are transferred/moved to the work-in-process factory floor when needed for manufacturing, (2) finished goods are transferred/moved from the factory floor to the finished goods warehouse, and (3) finished goods leave the finished goods warehouse when they are sold.

Figure 1

Three Sections of a Manufacturing Company

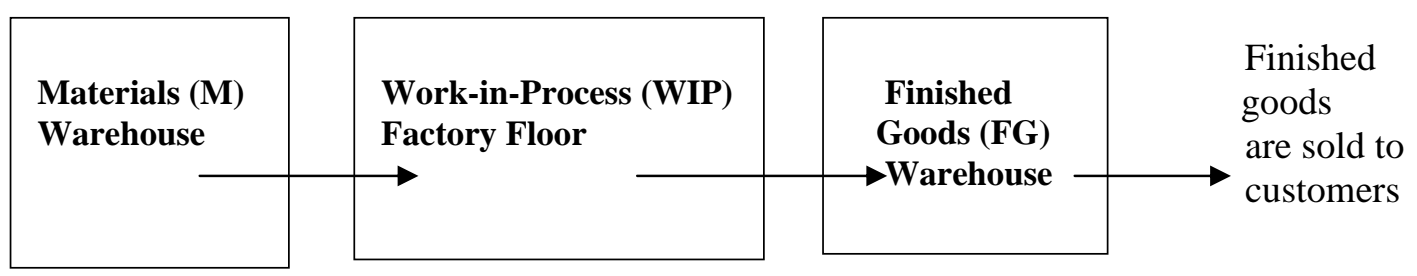

Next, the instructor introduces students to the general accounting equation:

Beginning balance + Increases - Decreases $=$ Ending balance

The instructor should tell students that this equation is commonly used in many of the statements that companies send out, such as credit card statements, utility bills, and bank statements. In a credit card statement, the beginning balance tells how much we owe the credit card company at the beginning of the accounting period, the increases come about when we use the credit card, and the decreases come about when we pay our credit card bill. The credit card company then calculates an ending balance following the above general accounting formula.

This general accounting equation also is used to keep track of what goes on in a company. In the job costing example, the accounting equation is used to keep track of the activities in each section of the company. The beginning balance tells how much assets (materials, work-in-process, finished goods) there are in each section of the company at the beginning of the accounting period. The increases(decreases) are the events that lead to the increases(decreases) in a section during the accounting period. ${ }^{5}$ For example, in the materials warehouse, increases in materials are because of purchases, and decreases are due to transfers (or requisitions) of materials out from the materials warehouse onto the work-in-process factory floor. Similarly, increases in finished goods arise from manufacturing (also called cost of goods manufactured), and decreases in finished goods occur from selling (also called cost of goods sold). These increases and decreases are shown in Figure 2.

The equations in Figure 2 are listed here:

Beginning $M+$ purchases - transfer to WIP = ending $M$

Beginning WIP + total manufacturing costs - COGM = ending WIP

Beginning FG + COGM - COGS = ending FG

The total manufacturing costs in equation (2) are just the materials (M), labor (L), and overheads (OH) used in manufacturing, that is:

5 The accounting period can be a week, a month, a quarter, or a year depending on how often the company does its management accounting reporting. 
Figure 2

Equations for Each Manufacturing Section of the Company

\begin{tabular}{|c|c|c|}
\hline $\begin{array}{l}\text { Materials (M) } \\
\text { Warehouse }\end{array}$ & $\begin{array}{l}\text { Work-in-Process (WIP) } \\
\text { Factory Floor }\end{array}$ & $\begin{array}{l}\text { Finished Goods } \\
\text { (FG) Warehouse }\end{array}$ \\
\hline $\begin{array}{l}\text { Beginning balance } \\
+ \text { Purchases }\end{array}$ & $\begin{array}{l}\text { Beginning balance } \\
+ \text { Total manufacturing costs }\end{array}$ & $\begin{array}{l}\text { Beginning balance } \\
++ \text { COGM }\end{array}$ \\
\hline$\frac{\text { - Transfer to WIP- }}{\text { Ending balance }}$ & $\frac{\text { - Transfer to FG (or COGM) }}{\text { Ending balance }}$ & - COGS \\
\hline
\end{tabular}

Note: $\quad$ COGM = Cost of Goods Manufactured.

COGS $=$ Cost of Goods Sold.

Arrows indicate cost flows.

Increases are denoted by "+” and decreases by “-."

Arrows indicate cost flows.

Since the materials, $\mathrm{M}$, in equation (2a) are the same materials transferred or requisitioned from the materials warehouse, equation (1) can be slightly modified as follows:

Beginning $M+$ purchases $-M=$ ending $M$

Thus, Figure 2 can be re-drawn as Figure 2a as follows:

Figure 2a

Equations for Each Manufacturing Section of the Company

\begin{tabular}{|c|c|c|c|}
\hline Materials (M) Warehouse & $\begin{array}{l}\text { Work-in-Process (WIP) } \\
\text { Factory Floor }\end{array}$ & $\begin{array}{l}\text { Finished Goods } \\
\text { (FG) Warehouse }\end{array}$ & \\
\hline $\begin{array}{l}\text { Beginning balance } \\
+ \text { Purchases } \\
\text { - Transfer to WIP (or M) }\end{array}$ & $\begin{array}{l}\text { Beginning balance } \\
+ \text { Total manufacturing costs } \\
\quad(\text { or } \mathrm{M}+\mathrm{L}+\mathrm{OH})\end{array}$ & $\begin{array}{l}\text { Beginning balance } \\
+ \text { COGM } \\
\longrightarrow \text { COGS }\end{array}$ & $\begin{array}{l}\rightarrow \text { COGS in } \\
\text { Income }\end{array}$ \\
\hline Ending balance & $\frac{\text { - Transfer to FG (or COGM) }}{\text { Ending balance }}$ & Ending balance & Statement \\
\hline
\end{tabular}

Note: $\quad \mathrm{M}=$ Materials used, $\mathrm{L}=$ Labor used, $\mathrm{OH}=$ Overhead or miscellaneous manufacturing costs.

COGM = Cost of Goods Manufactured.

COGS $=$ Cost of Goods Sold.

Increases are denoted by “+” and decreases by “-.”

Arrows indicate cost flows. 
As noted earlier, the arrows denote the physical movements within the company and they indicate that the sections within the company are connected; thus, the equations in Figure 2a also can be connected or combined. Students should learn how to combine all the equations in Figure 2a into a report called the Schedule of Cost of Goods Sold. This report details what goes on in the company during an accounting period and how the company determines its Cost of Goods Sold. Cost of Goods Sold (or COGS) will be reported on the Income Statement to derive the income for the company. Although a few management accounting textbooks show the Schedule of Cost of Goods Sold, they often do not explain how this Schedule was derived. ${ }^{6}$

The mathematical steps in deriving the Schedule of Cost of Goods Sold are as follows:

Rearrange equations (1a), (2a), and (3):

$M=$ Beginning $M+$ purchases - ending $M$

COGM = Beginning WIP $+(M+L+O H)$ - ending WIP

COGS = Beginning FG + COGM - ending FG

Substitute (2b) into (3a) to get (4):

COGS $=$ Beginning FG + (beginning WIP $+\{M+L+O H\}-$ ending WIP) - ending FG

Substitute (1a) into (4) to get the equation (5) for the Schedule of Cost of Goods Sold:

$$
\begin{aligned}
\text { COGS }=\text { Beginning FG } & + \text { (beginning WIP }+\{\text { [beginning } M+\text { purchases }- \text { ending } M] \\
& +L+O H\}- \text { ending WIP })- \text { ending } F G
\end{aligned}
$$
remember:

The above Schedule of Cost of Goods Sold, equation (5), may be rearranged to make it easier to

$$
\begin{aligned}
\text { COGS }= & (\text { Beginning } M+\text { beginning WIP }+ \text { beginning FG })- \\
& (\text { ending } M+\text { ending WIP }+ \text { ending FG })+(\text { purchases }+L+O H)
\end{aligned}
$$

Equations (5) and (5a) help students to understand how Cost of Goods Sold (or COGS) is determined and how it is affected by all the sections in the company.

Since COGS affects the bottom-line of the company via the income statement equation, sales COGS = gross profit, equation (5a) can be used in decision making. For example, if the company wants to reduce or cut costs, it can:

1. Reduce beginning balances (of M, WIP, FG).

2. Increase ending balances (of M, WIP, FG).

3. Reduce purchases of materials.

4. Reduce the use of labor.

5. Reduce the costs of overheads.

$6 \quad$ Textbooks usually explain job order costing using journal entries and ledgers. 
Moreover, equation (5a) can be used to explain why a company can increase its income by just building up its inventory of finished goods (FG). Equation (5a) shows that when ending FG is greater than beginning FG, this results in a reduced COGS and subsequently an increase in income. However, equation (5a) is not used in management accounting textbooks. In these textbooks, in the chapter on Variable Costing, authors compare the income statement under the Variable Costing method (which has a Contribution Margin) with the income statement under the Absorption Costing method (which has a COGS) to show how the income under the Absorption Costing method can be distorted (by comparing to the income under the Variable Costing method) whenever ending FG and beginning FG are not equal.

Equation (5a) also explains how modern management techniques affect Cost of Goods Sold. In the Just-in-Time technique, the company minimizes inventory by aiming for zero beginning and ending balances of materials, work-in-process, and finished goods. In the Activity-Based-Costing (or ABC) technique, the company tries to assess what gives rise (or drives) overheads; by identifying cost drivers (that is, the causes of overheads), the company can control/reduce overheads. In the Total Quality Management technique, the company focuses on the other two elements of manufacturing costs, that is, improving the quality of materials purchased and having good workers.

\section{Phase 3: Solve Equations Using Spreadsheet}

Instructors should assign spreadsheet exercises for students to do. Students should be assigned to tabulate the equation in the form of a spreadsheet report by using EXCEL or other available spreadsheet software. Table 1 presents an example of the layout of the work-in-process (WIP) equation (2a). Similar reports can be prepared for other equations. By preparing spreadsheet reports, students get to think about what a report should look like, how it is set up (e.g., following some equation), and how the columns and rows should be labeled.

\section{Table 1}

\section{Job Order Costing in The Work-In-Process (WIP) Section}

\begin{tabular}{|c|c|c|c|c|c|}
\hline & $\underline{\text { Job \#1 }}$ & $\underline{\text { Job \#2 }}$ & $\underline{\text { Job \#3 }}$ & $\underline{\text { Job \#4 }}$ & $\underline{\text { Total }}$ \\
\hline Beginning balance & $\$ 10$ & $\$ 22$ & $\$ 0$ & $\$ 0$ & $\$ 32$ \\
\hline \multicolumn{6}{|l|}{ + Total manufacturing costs: } \\
\hline Direct materials & 4 & 6 & 8 & 20 & 38 \\
\hline Direct labor & 8 & 10 & 10 & 40 & 68 \\
\hline Overheads & 16 & 10 & 11 & 21 & 58 \\
\hline Total costs & 28 & 26 & 29 & 81 & 164 \\
\hline - Transfer to WIP (or COGM) & ? & ? & ? & 0 & ? \\
\hline = Ending balance & 0 & 0 & 0 & ? & ? \\
\hline
\end{tabular}

Note: $\quad$ COGM $=$ Cost of goods manufactured . Jobs \#1 to \#3 were completed (that is, ending balance is 0 ). Job \#4 was not completed (that is, transfer to FG is O). The missing (?) numbers are solved using the equation:

Beginning balance + total manufacturing costs $-\mathrm{COGM}=$ ending balance 
Once the job order costing equations are tabulated in the form of a spreadsheet report, students practice solving the equations repetitively by using data from various companies. The instructor can make use of the company data that are usually available either within or at the end of a particular chapter of a management accounting textbook. The students fill in the available data for the equations and solve the missing variables. This reiterative process of solving the same equations with different data helps the students to think more deeply and extensively the intra-relationships among the variables in the equations for a variety of companies.

\section{Phase 4: Recycle Equations}

Equations should be recycled across multiple management accounting topics so that students get repeated exposures to same equations throughout the semester. By recycling equations, students get to understand how to apply the same equations in another management topic. For example, the formula that represents Finished Goods in job order costing:

Beginning balance + COGM - COGS $=$ Ending balance dollars $^{7}$

can be recycled for use in the topic of budgeting. The above equation is reworded from "dollars" to "number of units," as the latter is of interest in budgeting:

Beginning balance + Units to be Manufactured/Produced - Units to be Sold = Ending balance

(3) in

units

For spreadsheet presentation, the above equation is rearranged as follows:

Units to be sold + Ending balance - Beginning balance $=$ Units to be produced

The production budget, equation (3b), is used in almost all management accounting textbooks. Thus, a formula that is used for reporting purposes (determining COGS in job order costing) can also be used for planning purposes (determining the production budget). By using the same equation consistently across different management accounting topics, it helps the students to think more deeply and extensively the inter-relationships among management accounting topics.

\section{The Relationships between the DEIA and Learning}

An instructor (one of the authors) experimented using the DEIA to teach three introductory management accounting classes at a large public university in California. Data were collected from 79 students to determine the relationship between the DEIA and the student's learning and recommendation of the DEIA.

$7 \quad$ COGM and COGS have the word "costs," and costs are measured in dollars. 


\section{Data Collection}

Data were collected by way of a simple questionnaire administered to the students. Five questions (variables) relating to the learning of equations captured the DEIA as follows:

1. When an equation is used to represent a management accounting topic, the equation helps me to understand that topic. (EQNHELP)

2. Overall, when I read the equations, I understood what they meant. (USTDEQN)

3. When it comes to examinations, I usually can remember which equation is appropriate for a given accounting topic. (EQN4EXAM)

4. When it comes to filling in the equations with company data from the exercises/problems at the end of the chapter, I usually have no difficulty. (FILLEQN)

5. Overall, I do not have difficulty solving the equations. (SOLVEQN)

The students were asked to indicate the extent of their agreement with the five questions on a 7point scale (1 = disagree strongly, 7 = agree strongly).

A sixth question captured the students' recommendation of the continuation of the DEIA. The question is: I would recommend that the instructor continue to use this teaching approach. The students were asked to indicate their extent of agreement on a 7-point scale $(1=$ disagree strongly, $7=$ agree strongly). Finally, the students' course grades ( $1=\mathrm{F}, 4=\mathrm{A})$ were used to indicate their learning in the introductory management accounting course.

\section{Structural Equation Modeling}

Structural equation modeling (Arbuckle 1999) was used to determine the relationship between the DEIA and the students' learning and recommendation. An unobservable construct, called EQUATION, was set up for the five questions relating to the learning of the equations that capture the DEIA. The results of the structural equation modeling are presented in Figure 3. 


\section{Figure 3 \\ Structural Equation Modeling Of The Relationships Between The DEIA and Students' Performance and Recommendation}

Note: $\quad$ Chi-square $=3.098$; Degrees of freedom $=5$; Probability level $=0.685^{8}$

All the five measures were significantly and positively related to EQUATION, which in turn was significantly and positively related to the students' recommendation and grades. Thus, an overall interpretation of the model was that the DEIA was positively related to the students' learning of introductory management accounting, and that the students were positive about being taught introductory management accounting under the DEIA.

\section{Summary}

This paper describes a DEIA that promotes deep-elaborative learning of introductory management accounting for business students. Using structural equation modeling, the paper reports a positive relationship between DEIA and the students' learning of introductory management accounting. The model also shows that students were positive about being taught under the DEIA.

\footnotetext{
$8 \quad$ In Structural Equation Modeling, when a probability level is greater than 0.05, it means that the model is correct or significant (Arbuckle and Wothke, 1999, p. 343).
} 


\section{References}

Arbuckle, J.L. (1999). AMOS 4: Structural Equation Modeling Software. SmallWaters Corporation, Chicago.

Arbuckle, J.L, and W. Wothke. (1999). AMOS 4.0: User's Guide. SmallWaters Corporation, Chicago.

Böer, G. (2000). “Management Accounting Education: Yesterday, Today, and Tomorrow,” Issues in Accounting Education, 15 (2), 313-334.

Choo, F., and K.B. Tan. (1990). "A Note on the Academic Performance of Deep-elaborative versus Shallow-reiterative Information Processing Students,” Accounting and Finance, (30), 67-82.

Choo, F., and K.B. Tan. (1995). "Effect of Cognitive Elaboration on Accounting Students' Acquisition of Auditing Expertise,” Issues in Accounting Education, 10 (1), 27-45. 